\title{
COMPLEX URBAN SIMULATIONS AND SUSTAINABLE URBAN PLANNING WITH SPATIAL AND SOCIAL IMPLICATIONS
}

\author{
T. Becker ${ }^{\text {a,*, S. Boschert }}{ }^{\mathrm{b}}$, L. Hempel $^{\mathrm{c}}$, S. Höffken ${ }^{\mathrm{d}}$, B. Obst ${ }^{\mathrm{b}}$ \\ ${ }^{a}$ Institute for Geodesy und Geoinformation, Technische Universität Berlin, Germany - thomas.becker@tu-berlin.de \\ ${ }^{\mathrm{b}}$ Corporate Technology CT RTC AUC MSP-DE, Siemens AG, Germany - (stefan.boschert; birgit.obst)@siemens.com \\ ${ }^{\mathrm{c}}$ Center for Technology and Society, Technische Universität Berlin, Germany - hempel@ztg.tu-berlin.de \\ ${ }^{\mathrm{d}}$ CPE, Technische Universität Kaiserslautern, Germany, s.hoeffken@ rhrk.uni-kl.de
}

Commission II, WG II/2

KEY WORDS: city model, simulation, urban, spatial and social implication, city system model

\begin{abstract}
:
Cities can be seen as complex systems of heterogeneous processes with a high variety of different influences (e.g. social, infrastructural, economic, and political impacts). This especially applies for tasks concerning urban development of existing assets. The optimization of traffic flows, reduction of emissions, improvement of energy efficiency, but also urban climate and landscape planning issues require the involvement of many different actors, balancing different perspectives, and divergent claims. The increasing complexities of planning and decision processes make high demands on professionals of various disciplines, government departments, and municipal decision-makers. In the long term, topics like urban resilience, energy management, risk and resource management have to be taken into account and reflected in future projects, but always related to socio-spatial and governmental aspects. Accordingly, it is important to develop models to be able to understand and analyze the outcomes and effects of governmental measures and planning to the urban environment. Thus, a more systematic approach is needed - going away from welldefined city models to city system models. The purpose is to describe urban processes not only quantitatively, but to grasp their qualitative complexity and interdependencies, by modeling and simulating existing urban systems. This contribution will present the City System Model (CSM) concept closely related to an Urban Energy Planning use case, will highlight the methodology, and focus on first results and findings from an ongoing interdisciplinary research project and use case to improve the basis of information for decision-makers and politicians about urban planning decisions.
\end{abstract}

\section{INTRODUCTION AND MOTIVATION}

Since urban development was traditionally heavily influenced by expert knowledge of specific domains, today a more holistic view of the city is required, given by the increasing mutual linkage of urban processes. The growing number of interdependencies in urban environments means that planning topics cannot be solved singularly. In fact, due to increasing complexity an integrative urban planning is needed. Moreover, the importance of population trends increases so that the redevelopment of existing urban structures, such as buildings, parks, etc. will become a greater weight. Therefore, interdisciplinary solutions always require participatory approaches as well, which allow for the early integration of stakeholders in the decision-making processes at all levels of scale.

An integrated modeling and simulation approach, which takes into account the complexity of urban processes, the planning tasks and the respective stakeholder perspectives can serve as decision and planning assistance and will heavily increase the acceptance by inhabitants and parties involved. It is important to reduce the complexity of processes so that an optimal decision making process is ensured. Moreover, the consequences of decisions or measures undertaken by actors involved have to be made visible and communicated as understandable as possible. Multidimensional assessment processes must be made clear, without falling into the simplification trap. Only going that way it is possible to contribute essentially to consensus building and structured debates in urban development.

Semantic city models will play a significant role in this field. However, questions such as - "What happens to the inhabitants structure if we apply district wide building restoration?" or
"Which measures can be applied or are suitable if we want to reduce the carbon dioxide emission of our city by 20 percent?" cannot be answered by "simple" simulations and existing city models. These approaches do not yet support neither complex citywide simulations nor do they include socio-spatial implications or are eligible to forecast effects to the urban system by applying governmental measures.

Accordingly, a logical development step is - the transformation of existing city models onto city system models that link spatial entities of the city with additional data, particularly related to social indicators and economic aspects. The purpose of such models is to describe urban processes not only quantitatively but also qualitatively by connecting them to specific spatial objects. This allows for a better mapping of urban processes and for the optimization of decision-making processes by examining decision alternatives and decision paths in terms of their sociospatial effects. Those systems can only be seen as spatial decision support systems, since the dynamics of socio-spatial aspects are not fully determinable.

Thus, a model is required that is able to handle relations between socio-spatial contexts and spatial objects on any meaningful scale level, so that requirements can be linked to flexible planning in a city system model. This forms the motivation for the concept of the City System Model (CSM). A system, here in particular a city, consists of a set of entities and processes that interact with one another, and can be viewed as a whole that interacts with its external environment.

The paper will present existing modeling approaches regarding the urban environment in chapter 2, will present the City System Model concept will highlight the methodology in chapter 3 and furthermore will emphasize first findings and results of a case study applying a "simple" simulation scenario

\footnotetext{
* Corresponding author.
} 
on a part of the city of Berlin (chapter 4). Finally, the authors will point out conclusions and future works in the field of CSM.

\section{RELATED WORK}

\subsection{CityGML}

The City Geography Markup Language (CityGML) (Gröger et al. 2012) as international standard for the representation and exchange of semantic 3D city models specifies classes and relations for the most relevant city objects in an object-oriented way. It includes geometrical, topological, semantical, and appearance properties, generalization and aggregation hierarchies between object classes as well as thematic relations between city objects. The standard defines a common information model and data exchange format for 3D urban and rural objects. The thematic information provided by CityGML go beyond simple 3D visualization and is required for sophisticated analysis tasks in different application domains like simulations, urban data mining, facility management, and thematic inquiries. The CityGML language core does not provide explicit attributes e.g. for modeling energy consumption of buildings, utility infrastructure distribution and capacities, and power stations. However, objects, which are not explicitly covered by the specification document, can be represented using the concept of generic objects and attributes or by the definition of an extension for specific applications through so-called Application Domain Extensions (ADE).

\subsection{Urban Energy Planning}

Urban energy planning is a holistic process (UN Habitat, 2009) that has to deal with simulation of planning alternatives in conjunction with decision making regarding the suitability of measures. The suitability of measures can be evaluated (UN Habitat, 2009) according to indicators. Indicators can be understood as individual variables or variables that are a function of other variables to summarize, simplify, quantify, measure, and communicate relevant information. Indicators are used to make significant phenomena visible or perceptible in a transparent way (Gallopín, 1997; Carneiro, 2011). Thus, Krüger \& Kolbe (2012) propose an EnergyADE for the explicit storage of these indicators in relation to the accordant city object. Additionally to already existing values of a building in CityGML they define elementary indicators such as NumberOfStoreys, AccomodationUnits and so on. Complex indicators such as building height or heated volume are used to describe complex function on the related building. The Heating Energy Consumption for example is a function of attributes Construction Year, Assignable Area and Building Type. The proposed EnergyADE allows for classification and aggregation of indexes and indicators. Since this approach indicates to be systematic, itlacks of systematic elements (no internal or external influences). Moreover, the concrete usage of the proposed indicators within a City GML dataset and especially in an urban planning scenario is unclear.

Yeo et al. (2013) have presented an already implemented system based on several databases interacting with each other. They use information about the urban space, the microclimate, and include estimates about existing end-user devices such as washing machines, TV sets etc. to be able to determine the energy demand for a whole district or a city. However, the evaluation of their forecasting is not done yet and the integration into a bigger urban context is missing. They neglect external effects that result from changes within the building structure (e.g. insulation of buildings) as well as the effects onto changes of the rental fees for apartments and its impacts on inhabitant's structure. To summarize they omit the global system view and neglect parts of a city system interacting with each other. Moreover, the interconnectivity among system parts increases the demands onto the city / city entities itself. A city, a building, or district can no longer be treated as stand-alone, but behave as part of a larger whole that includes other systems. An example for such an inclusion of systems are IFC buildings and their included systems such as utilities, HVAC, etc.. As already known from CityGML are buildings amongst others an essential entity of a city and thus part of the city system and urban infrastructures as well. The interaction between urban entities is presented and introduced by Madlener and Sunak (2011). They describe the impacts of urbanization on urban structures and energy demand and point out various effects and mechanisms (see fig. 1) that influence urban structures and human behavior.

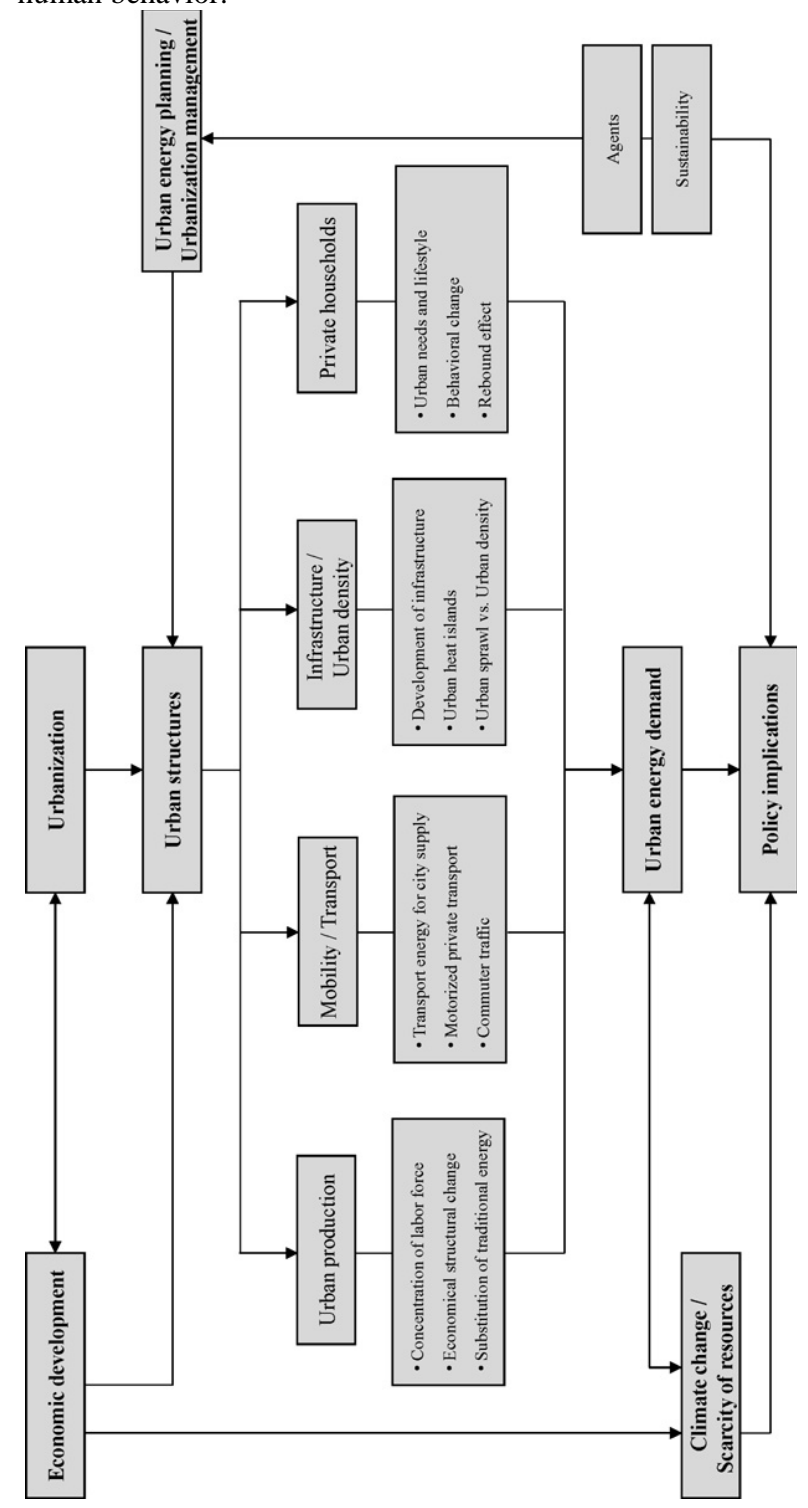

Figure 1. Impacts of urbanization on urban structures and energy demand (taken from Madlener and Sunak (2011))

They conclude with "In order to manage urbanization and to mitigate increasing energy demand in developing countries, particularly with regard to emerging megacities and the tendency of 'overurbanization', policy measures have to be multidimensional, participatory, and multi-sectoral." (Madlener and Sunak (2011). However, they lack of a modeling approach. 
Thus, an approach determining the urban energy demand has to take into account the bigger context - it must be system aware. A city as a system-of-system where all systems are interacting with each other should thus be modeled and represented as a system, as presented in the next sections.

\section{CASE STUDY: IMPACT OF AN ENERGETIC NEIGHBORHOOD REDEVELOPMENT ON THE SOCIAL STRUCTURE}

In this section we present a comparative scenario respectively simulation to the urban planning use case for our system modeling scenario. We used this scenario as a test case to get a better understanding of the relations between city entities, in this case buildings and the inhabitant's structure of those buildings. The simulation can be classified according to fig. 3 as Level 2 simulation. For developing the City System Model (CSM) a part of Berlins' district Moabit around the Turmstraße was chosen as test area. This specific district is characterized on the one hand by different social developments and on the other hand through various residential areas. For this specific area urban information in terms of CityGML LOD 2 buildings as well as data from the Berlin Senate including the Social Index and residential locations are used. On the base of interviews with actors of urban planning factors on the socio-economic development of the area were identified. Thus, actor-specific perspectives were accurately determined, i.e. information for each actor regarding scale, themes, actor networks, and relevant data can be defined. To complement the database, inspections were carried out, so that in limited, non-representative extent information about building condition, number of tenants, remediation status, number of windows, etc. was available.

The specific project involved the simulation of relationships between political decisions, measures relating to energyefficient renovation of the housing stock and the resulting social impact. Therefore, the existing city model for the study area was accumulated by socio-spatial quantitative and qualitative data. The five milieus (compare the colored bars in figure 2), representing the social structure of the neighborhood were defined and indicators were determined which represent the influence of remedial measures to the respective milieus. The five milieus used in this scenario are as follows:

- Young-creative (violet)

- Migrants (red)

- Well-to-do (yellow)

- Traditionals (turquois)

- Precarious (pink)

Young-creatives are 18-27 years old, have a small income, do support energetic reconstruction of a building but do not have financial background for that. Migrants are 27-65 years old, are locally cross-linked, have medium income and behave neutral with respect to energetic reconstruction. Well-to-do's are a liberal-intellectual milieu with high income, city-wide crosslinked, mostly have a condominium and do highly support energetic reconstruction. Traditionals are more than 45 years old, have medium income, and have partly condominium' and behave neutral with respect to energetic reconstruction but do not have good financial background. Precarious are between 27 and 65 years old, are mostly unemployed and thus have a low income and lack in financial background for support of energetic reconstruction.

Based on literature and Internet research relationships between building age, status, cost of energy refurbishment, energy saving potentials as well as social consequences were defined and placed in operable formulas, on which the simulation was carried out. For example, it was shown how different incentive measures for building remediation (low-interest loans, rental fee share) on direct costs (rates) and indirect costs (energy costs) and the long term can alter the structural composition of the area. Thus in an extreme scenario - where the rehabilitation costs were allocated as maximum onto the rent - a significant change in the inhabitants distribution over the years is viewable. Instead, if the renovation is financed only through subsidies, only a slight change in the social structure (see fig. 2) is observable. As with any model, it is also important to consider the underlying model assumptions: the scope of the model.

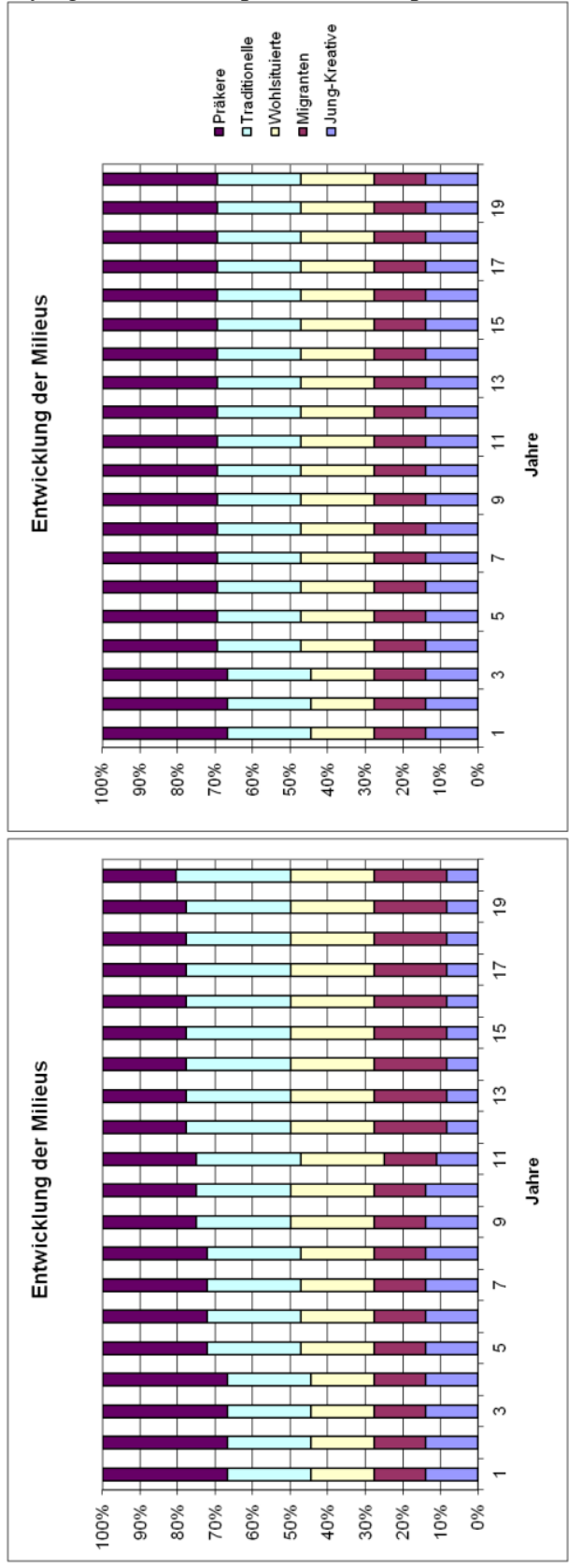

Figure 2. left / bottom: change in milieus by full allocation of insulation costs onto rental fee; right / top: slight change in milieus by having full subsidies

The present work can only be considered as a first step towards a quantitative description of the extremely complex system of city life in all its facets due to the additional assumptions and simplifications carried out and the low spatial coverage. However, qualitative information about the cause-effect 
relationships can be already derived from the simulation and can be used as indicator for a city system model and a related simulation. Out of that test case, we learned that changes on buildings due to energy consumption definitely would have an effect to the building energy consumption and to the inhabitant's structure as well. Thus, a system model for a city has to incorporate city entities like buildings, streets, higher aggregational objects like blocks, districts etc. and quantitative data like inhabitants structure, milieus, rental fee share, income per capita and more. These values will have an influence onto the measure that should be applied to the building and the measure itself will influence the quantitative values vice versa.

\section{THE CHALLENGE CSM AS REALIZATION OF A SYSTEM MODEL IN SYSML}

Each socio-spatial contextual level of a city contains a different number of actors, roles, and practices in relation to relevant objects. This means, in the field of urban planning, that the CSM contains per aggregation or planning level a unique object-based semantic. Thus, analysis needs are met and a bestfit simulation for each level of aggregation can be enabled. The big challenge is, in particular, to make different levels of aggregation mutually translatable in such a way that only relevant and editable meanings are visible to the user, while the holistic view remains present overall at any time in the background. The integrated approach is intended to consider the complexity of urban processes, the planning tasks, and the respective stakeholder perspectives. Classical urban models are mainly based on spatial and object-related parameters, permitting city-wide "simple" simulations, for example, the calculation of energy saving and restoration potential (1st level fig. 3). Enhancing basic energy simulations (based on spatial and non-spatial parameters, such as storeys, number of inhabitants etc.), the CSM widens the possibilities for urban simulations in a horizontal and vertical dimension.

As part of the realization of the CSM socio-spatial dynamics has to be integrated in a way that social, economic and spatial parameters can be combined to simulate dependencies and impacts of measures in terms of a selected process in a particular area (2nd level fig. 3). At the third level, there is still a need to further expand the limited perspective on urban planning relevant topics by other processes or threads that are interacting with this specific perspective, such as transport and energy consumption including social dynamics. On this 3rd level - comparable to real-world complex city systems different groups of stakeholders and their ambitions have to be integrated and connected. This requires the possibility to simulate and analyze socio-spatial correlations. Thus, all complex subsystems of a city have to be considered in the model design phase.

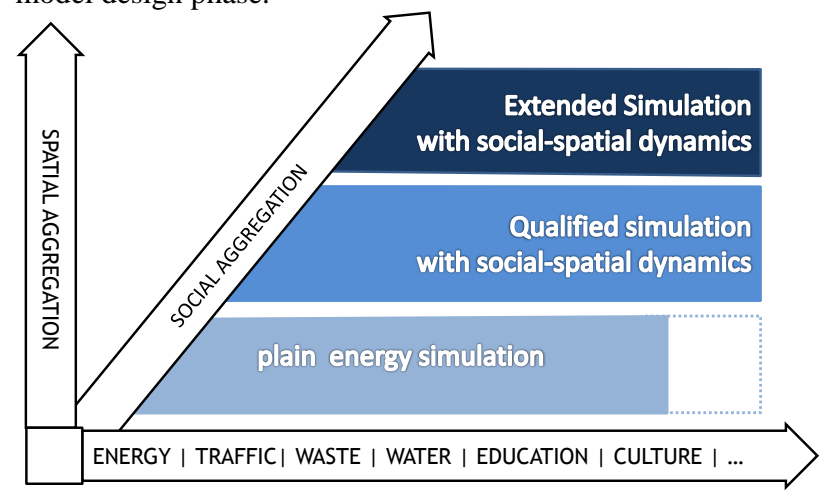

Figure 3. CSM as genesis of existing city models
On that level, switching between different levels of aggregation or scales is possible allowing using this information in complex simulations and analysis.

\subsection{SysML}

To be able to model the city as a system a more systems related engineering language should be chosen. CityGML for example is intended to describe the entities of a city on a sematicontological level. The interrelations between features are modeled on a topological level and internal or external effects of one entity of a city system onto another entity cannot be expressed by CityGML. Internal effects are those taking place within the entity itself such as the change of electrical lamps within a building onto the building's energy consumption or the building restoration onto the change of inhabitants structure of a building. An external effect occurs when for example environmental conditions or laws change which will have effects to the entities of the city. An example for that is the energy policy of the European Union, where in 2006 a reduction of $20 \%$ in primal energy was agreed. Those changes in law are external effects to the states, cities, and at least buildings of all European states.

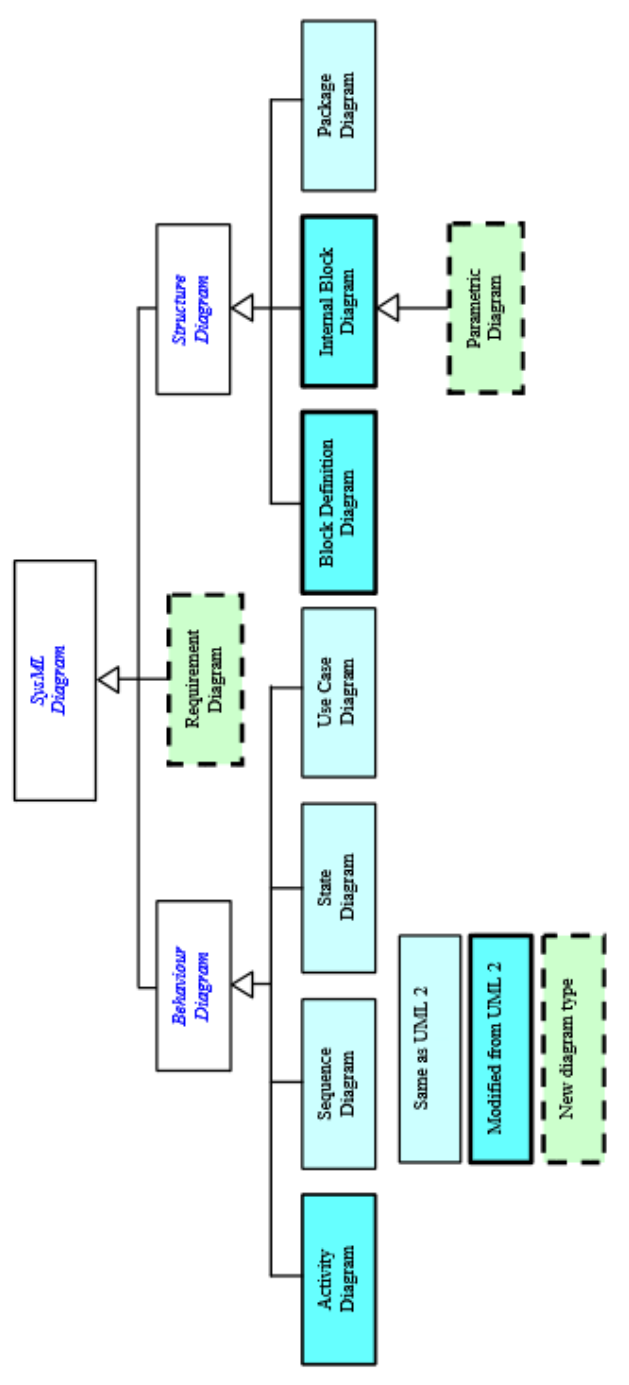

Figure 4. OMG SysML Diagram Taxonomy (Friedenthal et al, 2012) 
A more system related approach should integrate the interaction of parts of the system as well as the effects on the internal and external environment. The Systems Modeling Language (OMG SysML) is such an approach respectively language. SysML is an extension of UML and supports the specification, design, analysis, and verification of systems. "A system consists of elements that interact with one another, and can be viewed as a whole that interacts with its external environment." (Friedenthal et al, 2012). Designing and modelling of systems is multidisciplinary in order to develop a system that fulfills the stakeholder needs. The advantage of a system model is the mechanism to specify and integrate subsystems and components into the system and to maintain traceability between system and component requirements. Using SysML allows for integration into engineering analysis and simulation models such as Mathematica, MathWorks' Simulink, or OpenModelica. Instead of a geometric representation of a system, a SysML model represents the behavior, structure, properties, constraints, and requirements of the system. Model in this term means a representation of one or more concepts of a domain of interest that are or may be realized in the physical world.

Using SysML allows for representing the following aspects of systems, components, and other entities (Friedenthal et al, 2012):

- Structural composition, interconnection, and classification

- Function-based, message-based, and state-based behavior

- Constraints on the physical and performance properties

- Allocations between behavior, structure, and constraints

- Requirements and their relationships to other requirements, design elements, and test cases In the following, we present the first steps onto a more system related model of a city using SysML as a modeling language. SysML includes nine diagrams as it is shown in figure 4.

\subsection{Use case Energy savings and carbon dioxide reduction}

Use case diagrams are part of a SysML model and determine the extent of validity for that specific model. Since the demand for an overall city system is increasingly high, the required model complexity is high as well. Thus, initially a more simple use case was chosen to start the model design.

The Senate of a city decided to spend more money into social house building and adopted a new energy savings bill as well according to the European energy policy of 2006 (indicated by the black line going from the senate to the social house building and to the energy savings bill in fig.5).

The energy savings bill includes new rules for renewable energy, waste management, environmental relief programme, and so on. A major goal of the climate policy of the city is the reduction of $\mathrm{CO}_{2}$ emissions by 40 percent until the year 2020 as indicated by the dashed arrows. The change in $\mathrm{CO} 2$ emission and energy consumption will have effects to the utility networks of a city such as gas, water, heating, and power as well as to the transportation networks of the city. The energy savings bill in conjunction with governmental sponsorship stimulates the market and thus leads to major challenges regarding the planning of facilities and infrastructure. Planning include, for example, the choice of location of new power generating facilities like photovoltaic, geothermal and decentralized combined heat and power station, the widespread introduction

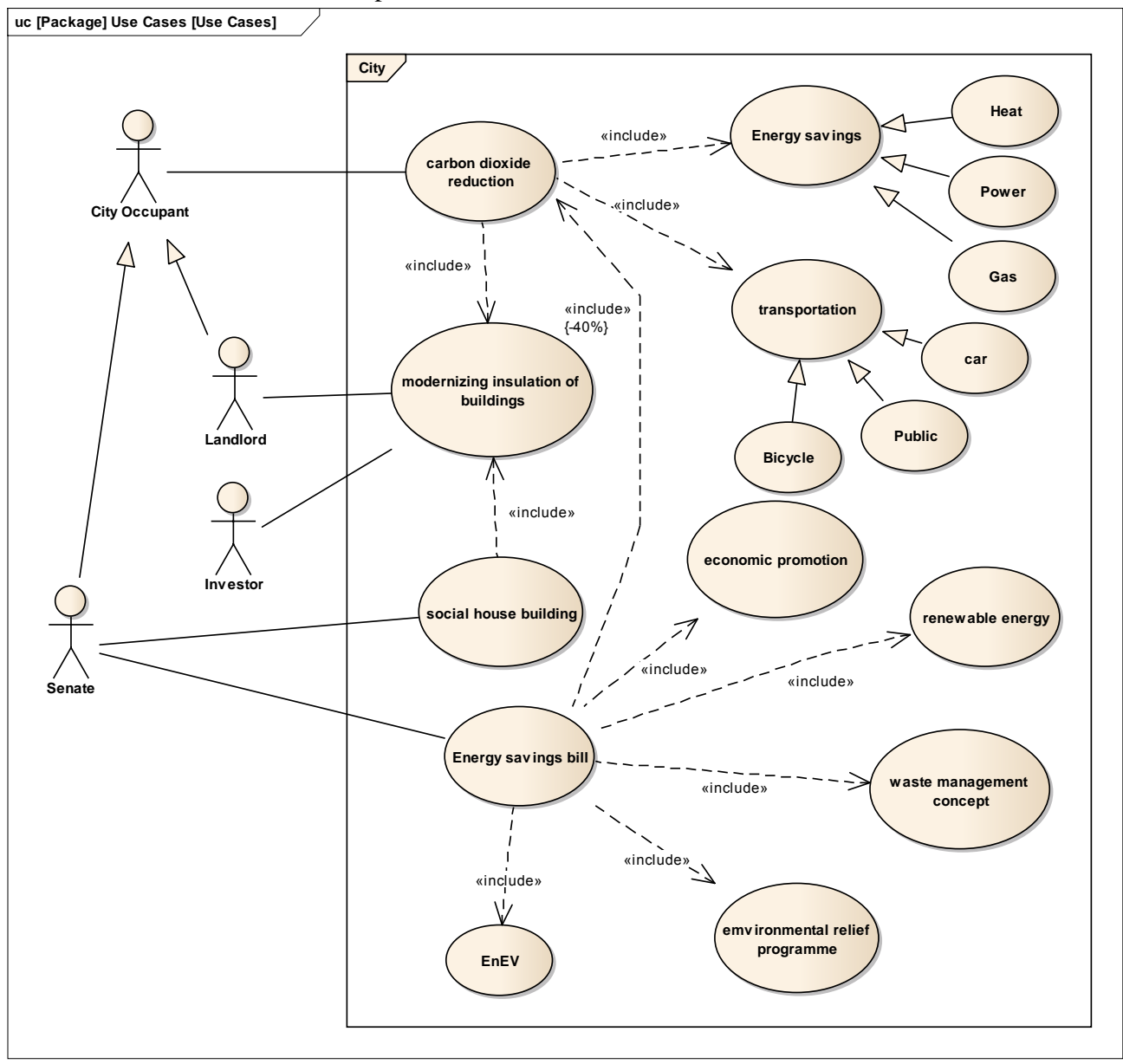

Figure 5. specific use case for using a city system model 
of e-mobility solutions and the consequently grid development as well as the planning of large-scale energetic building rehabilitations. The city resident will be a part of the measures but will also be affected by the measures. Hence, increasing rents or changes in population structure in his neighborhood might be a result of those measures. However, the final effects to the city occupant, utility networks, population structure, and urban planning cannot be estimated adhoc. As Mathiesen et al. (2011) and Sperling \& Möller (2012) point out using the EnergyPlan model in Denmark end-use energy savings and renewable energy systems do have effects to the socioeconomic costs. To be able to estimate those effects a model considering all entities involved and allowing the simulation and analysis is needed.

\subsection{City Development Domain}

Considering the urban area and urban development a city can be seen as a System-of-Systems (Lane and Bohn, 2013). A building as part of a city includes yet other systems such as a water system, electrical power system, a heating systems and so on. Each system is needed to care for a comfortable living or working area. However all these systems are connected to the external (city) environment via the building output, such as waste, energy, human beings and many more. The external environment interacts with the entities of a city and the entities itself do interact with the environment itself. It interacts with the system directly or indirectly. In system design and especially in the urban case it is important to identify what is external to the system.
The challenge is to combine the world of geoinformation respectively CityGML (highlighted in blue color) and the world of systems engineering. As figure 6 indicates, the entities defined in CityGML as part of the city are used and additional information describing the external and internal environment of our urban environment are integrated as well. CityGML is intended to give stakeholders, administration and programmer information about the existing entities of a city, their shape, function, and properties and so on. The interaction between objects and the city itself is not part of the CityGML standard but required for urban simulation. As shown in figure 2 many simulation and analysis tools use the entities itself - in this case energy simulation - but lack of simulating the effects on other urban entities or the city itself. The City Development Domain as shown in figure 6 is an initial approach to combine the both worlds - geoinformation and systems engineering. Due to readability and complexity not all objects of the model can be shown and presented here. As mentioned before CityGML can be seen as an inventory list of urban space and thus be part of the CityDevelopmentDomain. Becker et al. (2011, 2013), Kolbe (2009), Krüger et al. (2012), and Carrion et al. (2010) have shown the interrelation of city entities and city system and point out to consider the whole urban context for analysis and simulation. Figure 6 is a block definition diagram (bdd) according to SysML - that is used "to define blocks in terms of their features, and their structural relationships with other blocks." (Friedenthal et al., 2012). A block is the modular unit in SysML and used to describe a type of system, component, item, external entity, and many more. In case of

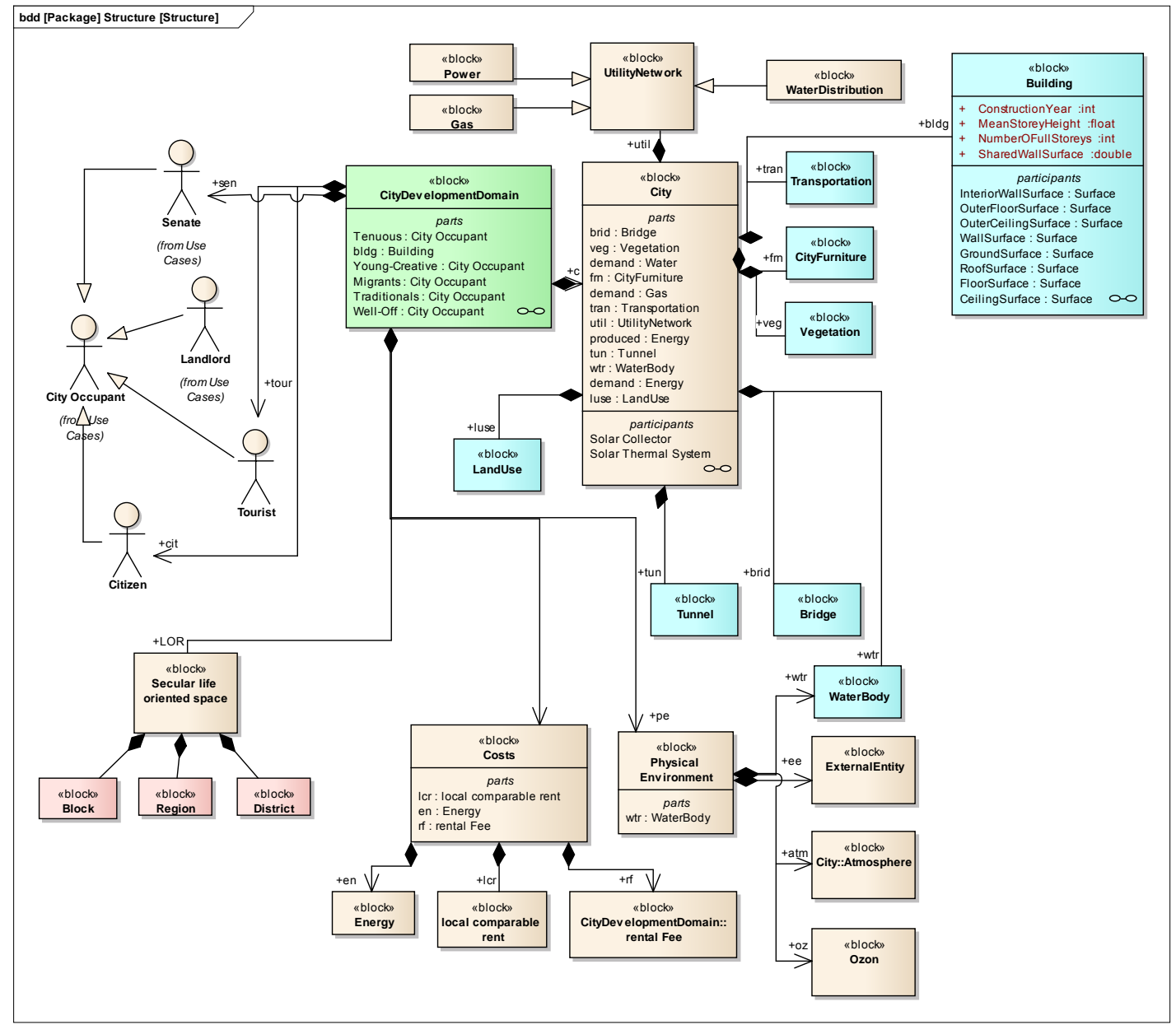

Figure 6. CityDevelopmentDomain block definition diagram - overall structure including the city and the external environment as well 
CityDevelopmentDomain the bdd is used to define relevant components and entities of the city. Each block therefore describes a set of uniquely identifiable instances that share the block's definition. According to Friedenthal et al. (2012) " $a$ block is defined by the features it owns, which may be subdivided into structural features and behavioural features." The term feature is not to be confused here with the ISO 19109 - where a feature is specified as abstraction of the real world. In SysML features can be differentiated into:

- structural features that define the internal structure and properties

- behavioral features that define how the feature interacts with its environment or modifies its state

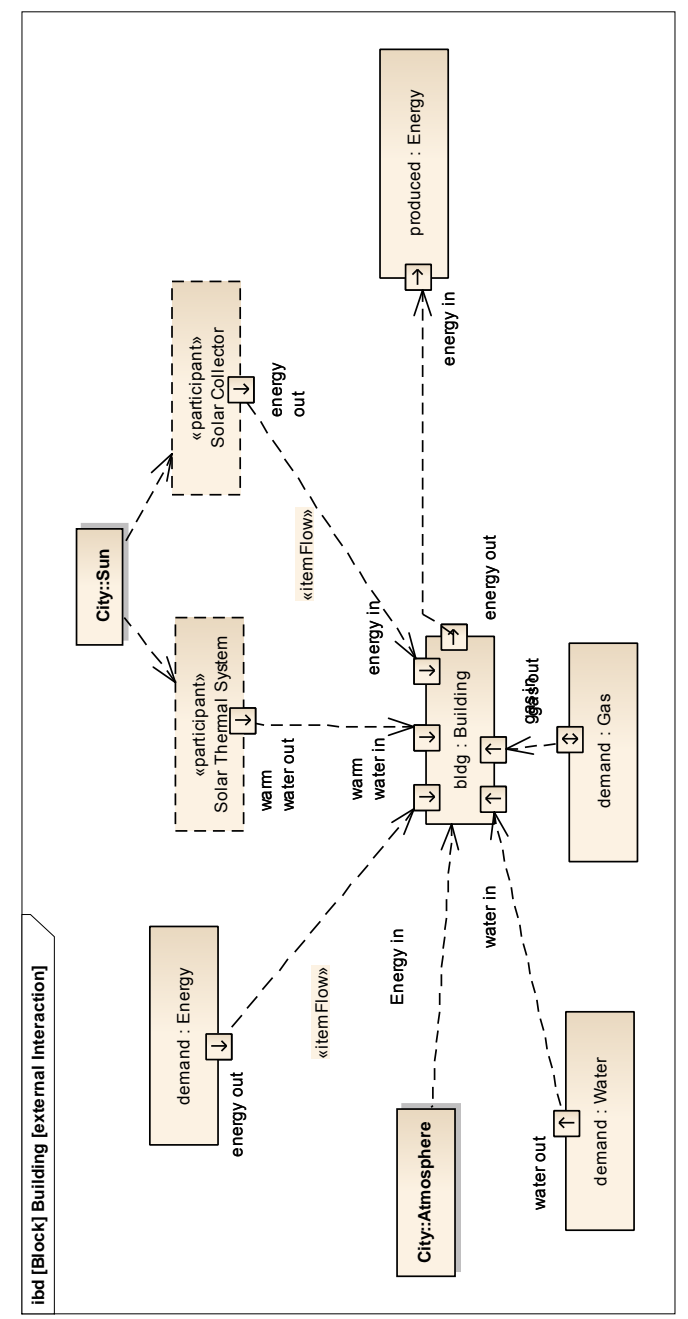

Figure 7. example (ibd) for external interaction of a building block with external blocks

Properties of a block are parts, references, and values. In the City Development Domain case - Surface and Energy are such kind of properties of the building block. They describe quantifiable physical, performance, and other characteristics of a block. Additionally a block owns, as it is in reality as well, a flow port (House Service Connector, see fig. 7 the input and output flow ports) for distributing gas, water, and energy from external environment into the building system. The external environments in this case are the utility networks of the City system. In figure 7 an internal block diagram (ibd) is shown that exemplarily illustrates how the parts and blocks are interconnected. The building is connected to the external environment via ports distributing water, energy, and gas into the building. Following the idea of Prosumption (Ritzer, G. and Jurgenson, N., 2010) a building does not only consume energy it can be also used to produce energy and warm water in terms of solar collectors and solar thermal systems. The energy gained from solar collectors will be fed into the energy supply system via the house service connector. Thus, a building is a consumer and producer as well.

\subsection{City development a question of scale}

The proposed model (CSM) focuses on different scales, from building level up to regional and interregional level - and furthermore the simulation and representation of interrelations between these different levels. The following dimensions have to be taken into account:
$\bullet$
- Infrastructural dimensions
- $\quad$ Social dimensions
- $\quad$ Governmental dimension

On the base of the CSM approach the concept of Local Living Contexts (LLC) has to be studied in order to model and integrate diverse dimensions, identify and analyze dependencies, simulate impacts of potentials measures and deduce governmental demands.

Krüger \& Kolbe (2012) and Carneiro (2011) point out that dealing with energy assessment and urban development is a matter of scale and thus a question of aggregation. Aggregation can be performed on a thematically or spatial level. Spatial aggregation is needed to express spatial hierarchies within a city like building - block - district - city. Thematic aggregation is needed to summarize or multiply values of specific subdomain to the domain itself e.g. city occupants are the sum of all existing milieus of a city. Since the spatial and thematic aggregation is comparable due to mathematical background the use of a more systematic approach in contrast to the already presented ones (Krüger \& Kolbe (2012), Carneiro (2011)) is given. Whereas thematic aggregation follows logical rules (membership to the same domain, etc.) the spatial aggregation follows spatial rules of a specific domain. The power network of a city and the administrative boundaries of a city do not share the same boundaries although they are subdivided into smaller spatial partitions such as districts or service areas. If we define the city (the boundary), itself as a common denominator we are able to define the mathematical equation for aggregating the attributes of the included objects (Krüger \& Kolbe, 2012). Thus the base for a mathematical description of the interrelation between a whole block and its parts is given.

\section{CONCLUSIONS AND FUTURE WORK}

Geoinformation enforces the communication between actors and promote the understanding among actors themselves (see Rambaldi et al. 2006). Especially the 3D modeling increases the understanding and promotes the capacity of proposed measures to participating stakeholders. Through a consistent analysis across multiple levels of aggregation, it is possible to demonstrate the advantage of urban planning measures for different actors. Thus, the effects are described both at the individual level as well as at operational and strategic levels to support decision-making. The City System Model is not only to be understood as a rigid data backbone, but as mapping of sociological, socio-economic and spatial planning factors. The mutual interaction or rather the dependencies between those factors will make such a model dynamic and flexible, and thus 
creates a much better approximation of our environment (reality) through geoinformation.

To be able to do "city-wide" simulation we have shown an initial approach of a combined semantic, informational, and systematic modeling for cities using SysML. The City System Model widens the possibilities for urban simulations in a horizontal and vertical dimension. Thus, social-spatial dynamics can be integrated and be part of the simulation. Future work will show how such a complex use case as presented in the case study can be mapped onto SysML and simulated using simulation software like OpenModelica. Future research and development will show how specific instances of CityObject can participate within a simulation scenario. The aggregation of simulation results onto a higher level of aggregation such as district or city will be set into focus. As far as we can see, the need of such a system model is increasingly high and standards as SysML do provide the required methods and tools to meet the needs and to provide better simulation results in the field of urban planning and development.

\section{REFERENCES}

Becker, T., Nagel, C., Kolbe, T. H., 2011. Integrated 3D Modeling of Multi-utility Networks and Their Interdependencies for Critical Infrastructure Analysis, In: Advances in $3 D$ Geo-Information Sciences. Kolbe, T. H., König, G., Nagel, C. eds, Springer Berlin, pp. 1-20.

Becker, T., Nagel, C., Kolbe, T. H., 2013. Semantic 3D Modeling of Multi-Utility Networks in Cities for Analysis and 3D Visualization. Progress and New Trends in 3D Geoinformation Sciences. Springer Berlin Heidelberg, 2013. 41-62.

Carrión, D., Lorenz, A., \& Kolbe, T. H., 2010. Estimation of the energetic rehabilitation state of buildings for the city of Berlin using a 3D city model represented in CityGML. In ISPRS Conference: International Conference on 3D Geoinformation. XXXVIII-4 pp. 31-35.

Carneiro, C., 2011. Extraction of Urban Environmental Quality Indicators using LiDAR-Based Digital Surface Models. Doctoral thesis, École polytechnique fédérale de Lausanne, Switzerland.

European policy, 2008. Communication from the Commision energy efficiency: delivering the $20 \%$ target, http://eurlex.europa.eu/LexUriServ/LexUriServ.do?uri=COM:2008:0772 :FIN:EN:PDF, (30 Jul..2013)

Friedenthal, S., Moore, A., Steiner, R.., 2012. A practical guide to SysML - The Systems Modeling Language, Morgan Kaufman OMG Press

Gröger, G., Kolbe, T. H., Nagel, C., Häfele, K.H., 2012. OpenGIS® City Geography Markup Language CityGML Encoding Standard, Version 2.0.0, OGC 08-007r2

Gallopín, G.C, 1997. Indicators and their use: information for decision-making. In Moldan, B., Billharz, S. Eds.. Sustainability Indicators: Report of the Project on Indicators of Sustainable Development. SCOPE 58, John Wiley \& Sons, Chichester, pp.13-27.

Krüger, A., Kolbe, T. H., 2012. Building Analysis for Urban Energy Planning using Key Indicators on Virtual 3D City Models - the Energy Atlas of Berlin. International Archives of
Photogrammetry, Remote Sensing and Spatial Information Sciences, XXII Congress of the International Society for Photogrammetry and Remote Sensing ISPRS 2012

Kolbe, T. H., 2009. Representing and exchanging 3D city models with CityGML. In: Lee, J., Zlatanova, S., Eds. 3D geoinformation sciences. Springer Berlin Heidelberg, 2009. 15-31.

Lane, J. A., Bohn, T., 2013, Using SysML modeling to understand and evolve systems of systems. Syst. Engin., 16: 87-98. doi: 10.1002/sys.21221

Madlener, R., Sunak, Y., 2011. Impacts of urbanization on urban structures and energy demand: What can we learn for urban energy planning and urbanization management?, Sustainable Cities and Society, 1(1), February 2011, pp. 45-53, ISSN 2210-6707, 10.1016/j.scs.2010.08.006

Mathiesen B.V., Lund H., Karlsson K., 2011. 100\% Renewable energy systems, climate mitigation and economic growth Applied Energy, 88(2), pp. 488-501.

Rambaldi, G.; Chambers, R.; McCall, M.; Fox, J., 2006. Practical ethics for PGIS practitioners, facilitators, technology intermediaries and researchers. PLA 54, pp..106-113, IIED, London.

Ritzer, G., \& Jurgenson, N., 2010. Production, Consumption, Prosumption The nature of capitalism in the age of the digital 'prosumer'. Journal of Consumer Culture, 101, pp. 13-36.

Sperling, K., Möller, B., 2012 End-use energy savings and district heating expansion in a local renewable energy system A short-term perspective, Applied Energy, Volume 92, April 2012, pp. 831-842, ISSN 0306-2619, 10.1016/j.apenergy.2011.08.040.

http://www.sciencedirect.com/science/article/pii/S03062619110 05502 (08 Jul. 2013)

UN Habitat, 2009. Sustainable Urban Energy Planning - A handbook for cities and town in developing countries, UNON, Publishing Services Section, Nairobi

Yeo, I., Yoon, S., Yee, J., 2013. Development of an urban energy demand forecasting system to support environmentally friendly urban planning, Applied Energy, Volume 110, October 2013, pp. 304-317, ISSN 0306-2619, 10.1016/j.apenergy.2013.04.065 (08 Jul. 2013)

\section{ACKNOWLEDGEMENTS}

We are grateful to the city of Berlin for providing us access to the Berlin city model, to all members of the project for their cooperation and especially to the participating actors and inhabitants for providing access to data and for fruitful discussions. 